\title{
CITYOPT PLANNING TOOL FOR ENERGY EFFICIENT CITIES
}

\author{
PEKKA TUOMINEN ${ }^{1}$, OLLI STENLUND ${ }^{1}$, CHARLOTTE MARGUERITE $^{2}$, NICOLAS PARDO-GARCIA ${ }^{2}$, \\ ELINA GRAHN ${ }^{1}$, JANNE HUVILINNA ${ }^{3}$ \& BRANISLAV IGLAR ${ }^{2}$ \\ ${ }^{1}$ VTT Technical Research Centre of Finland Ltd, FI-02044 VTT, Finland. \\ ${ }^{2}$ AIT Austrian Institute of Technology, Donau-City-Straße 1, Vienna, Austria. \\ ${ }^{3}$ Helen Ltd, Finland.
}

\begin{abstract}
There are many ways to integrate components (renewable energy sources, storages and energy efficient buildings) into a sustainable district or city and various corresponding urban strategies. However, the best solution is not always straightforward, and simulation tools are needed to select the optimal design according to specific criteria. The objective of the CITYOPT project is to create tools to support planning, designing and operating sustainable energy solutions in cities. In particular, the CITYOPT planning tool will support simulating, optimizing and analyzing various city planning alternatives. This holistic approach will integrate, among others, energy dynamics of local grids, buildings and consumption behavior and patterns, energy storages, and local energy production using renewables. The results from test use of the tool are presented alongside with business models for the case areas. For the Vienna case, the CITYOPT planning tool will allow to assess different possible designs for an industrial waste heat-based micro district heating network, supplying low-energy buildings. Existing renewable energy solutions and thermal storages (long and short term) are also considered. The Helsinki case consists of electricity storage solution planned in Kalasatama district and a combination of sustainable heating solutions planned for the Östersundom district.

Keywords: city, optimization, planning, simulation, tool.
\end{abstract}

\section{INTRODUCTION}

The current increase of urban population highlights the importance of the development of more sustainable urban areas which should be more energy and resource efficient. Specific issues have to be addressed, such as the use of renewable energy sources, the reduction of $\mathrm{CO}_{2}$ emissions, the engagement of stakeholders and users, administrative and regulatory barriers and new business models. There are many different ways to integrate components (renewable energy sources, storages and energy efficient buildings) into a sustainable district or city and various corresponding urban strategies. However, the best solution is not always straightforward, and simulation tools are also needed to select the optimal design according to specific criteria.

CITYOPT is a collaborative project supported by the European Commission through the Seventh Framework Programme (FP7). The objective is to create tools to support planning, designing and operating sustainable energy solutions in cities. In particular, the CITYOPT planning tool will support simulating, optimizing and analyzing various city planning alternatives. This holistic approach will integrate, among others, energy dynamics of local grids, buildings and consumption behaviour and patterns, energy storages, and local energy produc- 
tion using renewables. In this paper, the CITYOPT planning tool being developed, the methodology behind it and the test use results are presented alongside with business models for the case areas.

\subsection{Case areas}

\subsubsection{Vienna - reuse of waste heat}

The Viennese is based on three office buildings, which two are passive buildings with ground heat pumps and solar panels. They lie in close proximity to the climatic wind tunnel facilities of Rail Tec Arsenal GmbH (RTA). This facility tests the operation of vehicles in all weather conditions and specifically at low temperatures. During these tests, a huge amount of waste heat is rejected from chillers. The goal of this study case is to integrate the existing thermal energy supply systems of the office buildings with the waste heat rejected from RTA's climatic tunnel in one thermal network including a high-temperature and a low-temperature thermal storage to balance the heat production and demand and to deal with the different temperature levels of the waste heat rejected. A heat pump booster is also associated with the low-temperature storage to supply the network with the appropriate temperature level whenever necessary.

\subsubsection{Helsinki - electricity storage in Kalasatama}

The Kalasatama area, a district in eastern Helsinki, is a former harbour and industry area that is being redeveloped into a residential and business area. The area is about 175 hectares and when the completion of the conversion project is finished in the 2030s, there will be 20000 inhabitants and $390000 \mathrm{~m}^{2}$ of office premises and $45000 \mathrm{~m}^{2}$ of service buildings [1]. An electricity storage system is under consideration for the area.

\subsubsection{Helsinki - next generation district heating network in Östersundom}

The Östersundom area had 6400 inhabitants in the year 2013. Between the years 2020 and 2060, the area is expected to grow into a suburb of Helsinki with perhaps as many as 70000 inhabitants and 15000-30 000 new jobs [2]. Östersundom is a pilot site for environmentally friendly energy solutions and the business model created focuses on a possible solution for heat supply and heat storages in the area.

\section{METHODS}

\subsection{CITYOPT planning tool}

CITYOPT planning tool is a web application that can be used for comparison and optimization of different energy systems. The tool is implemented as web application that can be browsed with any web browser. The tool has been deployed on a publicly available web server and therefore can be reached over the Internet. PostGRES is used as database to store input data and results, which can be imported and exported later on. The solution has been developed with Java, Java Server Pages and Spring.

The energy system models that the tool optimizes are based on an Apros energy model that is imported to it. Currently, Apros simulator software is used to run the simulations on the server, but CITYOPT does necessitate the use of Apros. Other modelling software can also be interfaced to the CITYOPT tool. 
In CITOPT, the user can customize the model parameters and run the simulation repeatedly to test different values. The tool is also able to import and export data from and to other applications through CSV file format. This includes project, scenario and time series data. Also optimization problems can be imported and exported. The tool architecture is shown in Fig. 1.

CITYOPT planning tool uses 'projects' and 'scenarios' for storing the data. Project refers to a certain area that is being studied, while scenario refers to a certain set of parameters being applied to a project. The user is able to create and modify them. A project has all the basic data from the energy site like input, output and external parameters. Also metrics may be used for representing mathematical formulas. A project has usually many scenarios that describe the different comparable energy solutions. The scenario output parameter values are calculated by simulating the scenario. The user is also able to define project-related external parameters like energy prices.

The application has an authentication system and user authorisation for various user roles, namely administrator, expert, standard and guest. User roles restrict the usage of the application and make it more secure. For example, guests are allowed only to view data, not change it. Standard users may change some basic data of the project, but not all. Experts are able to change project-related data, but not to manage user accounts. Administrators are not restricted at all. In general, standard users have access only to certain projects that they have been given rights or they have created themselves.

The tool has two different optimization methods: database optimization and genetic algorithm (GA) optimization. Database optimization compares the existing scenarios in the project and finds the best scenario based on the user-defined objective function. It is able to minimize or maximize the value. Also the user is able to define constraints for parameters meaning minimum and maximum values. GA optimization is a more complex type of optimization. New scenarios are generated using random scenario changes and combinations of the scenario parameters. It may have many objective functions that can be optimized at the same time. The results are visualized in the form of a Pareto curve. If there is more than one objective function, then the user has to compare the objective function's results and decide which solution represents the actual optimum.

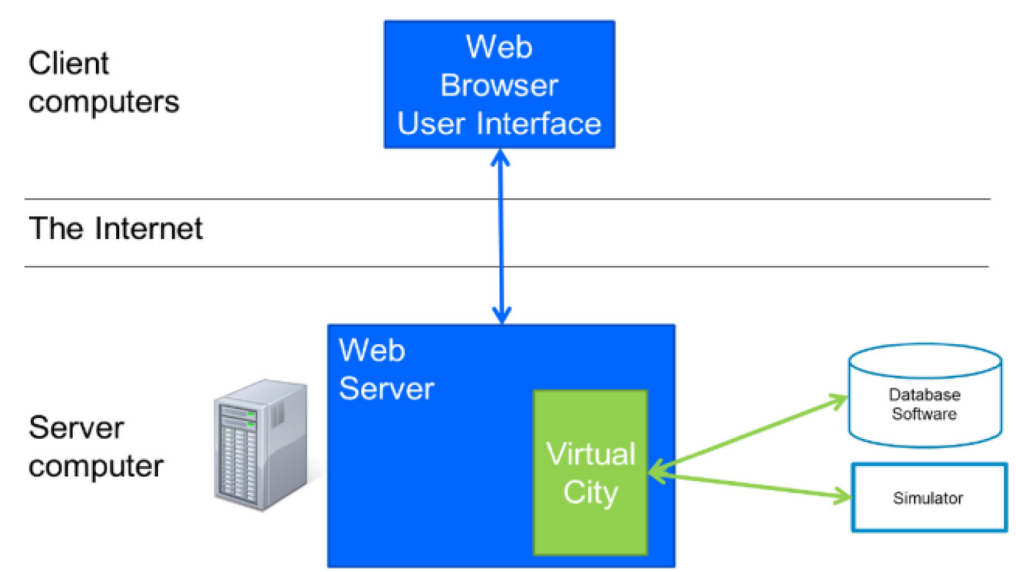

Figure 1: CITYOPT planning tool architecture. 
The tool can generate different kinds of visualization charts: time series chart, summary chart and genetic optimization chart. The time series chart can be used for visualizing output variable time series in a time series or scatter plot format. On the other hand, the summary chart may be used to compare metrics in different scenarios. It may be presented in scatter plot, bar chart or pie chart format. Genetic optimization chart shows the genetic optimization results for comparison. The results include the objective function values in each scenario. Two objective functions (one for each axis) can be compared at the same time. The tool is also able to view the simulation results in table format.

\subsection{Development of business models}

The business models developed are based on Osterwalder's business model canvas [3]. The purpose of the business model canvas is, on the one hand, to provide a framework for laying out the stakeholders, activities and resources needed to produce a value proposition and, on the other hand, to present the customer relationships and channels needed to deliver the value proposition to the customer segments. Also included are the cost structure and revenue streams. The idea is to provide a very concentrated description of a business model while making sure that all key issues are addressed. The business model canvas is presented in Fig. 2.

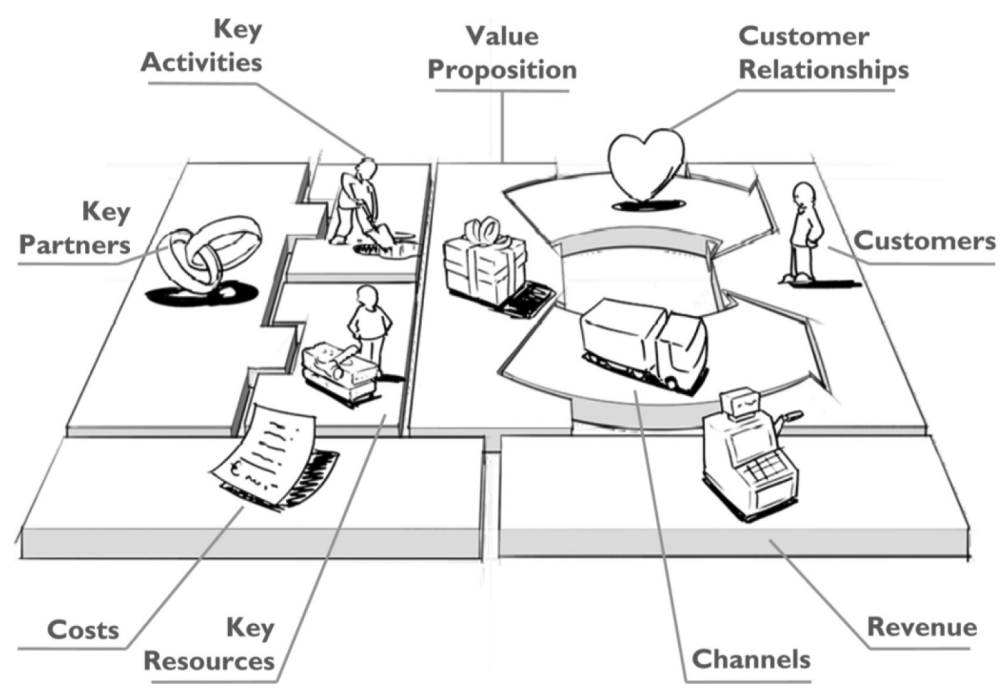

Figure 2: Key issues included in Osterwalder's business model canvas [4].

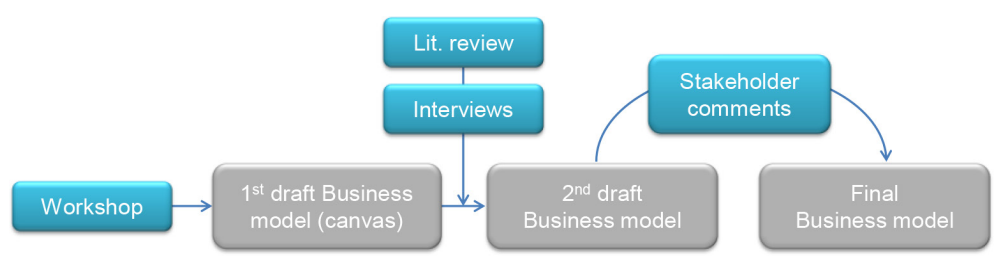

Figure 3: The process of developing business models. 
To involve the relevant stakeholders in the business model definition process, a series of activities has been executed in the three pilot cases. Business model development was structured as is presented in Fig. 3: the main data sources are workshops and interviews, along with other discussions with the stakeholders. This has been complemented with literature reviews to make sure that the development of business models was informed by past studies.

The workshops began the work of developing the business model, as the participants of the workshop provided their inputs to the business model canvas. This canvas worked as a first draft for the development, but the researchers modified the draft as they were informed by other sources, namely the literature review, interviews and discussions with the stakeholders. The following discussions with stakeholders included telephone and contextual interviews, both to involve stakeholders who could not attend the workshops and to better define the specific business model requirements. Interviews have been structured on a case-by-case basis, according to the specific needs. This resulted in a second draft of the business model. The draft has been sent to the stakeholders for comments, after which a final version of the business model has been crafted and is described in the results.

\section{RESULTS}

\subsection{Calculation example}

A calculation example is presented for the Viennese case as a demonstration of the use of the CITYOPT calculation tool. Eight scenarios are simulated, based on four network configurations and two price combinations, the heat pumps are operated with a minimum cost-based control strategy. The scenarios are described in Table 1. In Scenarios C and D, an additional building similar to the low-energy buildings is considered to assess an increase of the heat demand and a connection to the main district heating (DH) of Vienna is envisaged to weight back-up possibilities.

The two price combinations, based on the Viennese market, are the following: Prices 1 (electricity $€ 200 / \mathrm{MWh}$; heat $€ 40 / \mathrm{MWh}[5]$ ) and Prices 2 (electricity $€ 132 / \mathrm{MWh}$; heat $€ 66 / \mathrm{MWh}[6]$ ).

After running the simulations through CITYOPT, three different indicators are calculated separately, the primary energy used $(P E$ in $\mathrm{MWh})$, the $\mathrm{CO}_{2}$ emissions $\left(\mathrm{CO}_{2}\right.$ in tons/MWh) and the operating costs $(O C$ in $€ / \mathrm{MWh})$. To compare the scenarios in a more global way, an

Table 1: Description of the scenarios simulated.

\begin{tabular}{lccccccc}
\hline & $\begin{array}{l}\text { Standard } \\
\text { Buildings }\end{array}$ & $\begin{array}{l}\text { Low-energy } \\
\text { buildings }\end{array}$ & $\begin{array}{l}\text { Add. } \\
\text { Building }\end{array}$ & $\begin{array}{l}\text { Industrial } \\
\text { Waste Heat }\end{array}$ & $\begin{array}{l}\text { HT } \\
\text { Storage }\end{array}$ & $\begin{array}{l}\text { LT } \\
\text { Storage }\end{array}$ & $\begin{array}{l}\text { DH } \\
\text { Vienna }\end{array}$ \\
\hline $\begin{array}{l}\text { Configura- } \\
\text { tion A }\end{array}$ & $\mathrm{x}$ & $\mathrm{x}$ & & $\mathrm{x}$ & $\mathrm{x}$ & \\
$\begin{array}{l}\text { Configura- } \\
\text { tion B }\end{array}$ & $\mathrm{x}$ & $\mathrm{x}$ & & $\mathrm{x}$ & $\mathrm{x}$ & $\mathrm{x}$ & \\
$\begin{array}{l}\text { Configura- } \\
\text { tion C }\end{array}$ & $\mathrm{x}$ & $\mathrm{x}$ & $\mathrm{x}$ & $\mathrm{x}$ & $\mathrm{x}$ & & $\mathrm{x}$ \\
$\begin{array}{l}\text { Configura- } \\
\text { tion D }\end{array}$ & $\mathrm{x}$ & $\mathrm{x}$ & $\mathrm{x}$ & $\mathrm{x}$ & $\mathrm{x}$ & $\mathrm{x}$ & $\mathrm{x}$ \\
\hline
\end{tabular}




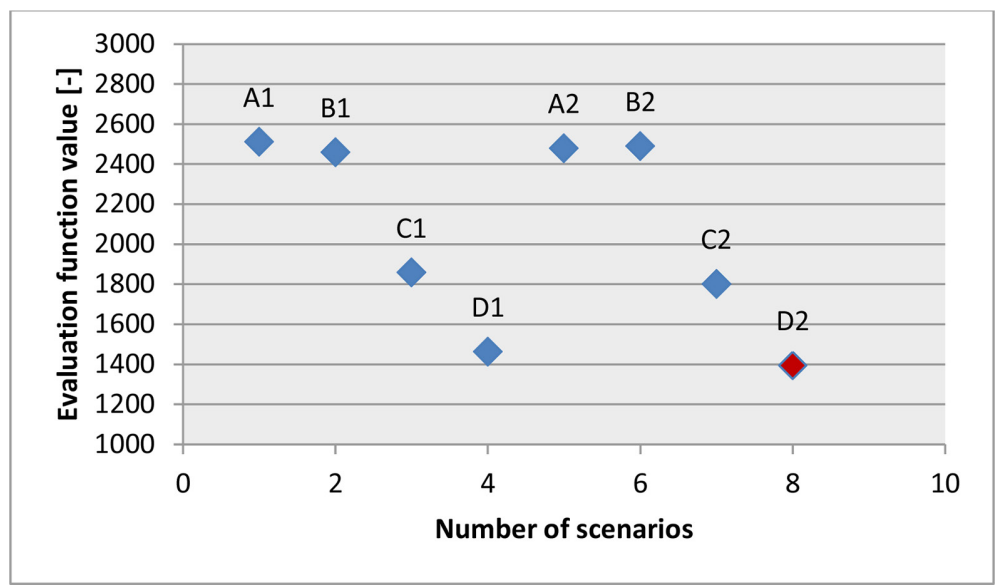

Figure 4: Evaluation function value for the scenarios simulated. A1 stands for the Configuration A run with the price combination 1. In red, the scenario D2 has the minimum value.

evaluation function, $f(x)$, (eqn 1) is calculated, based on the previous indicators and weighting factors which correspond to the importance given to each indicator.

$$
f(x)=P E+2 \quad \mathrm{CO}_{2}+3 \quad O C
$$

All the indicators and evaluation function values are stored in the database and can be used in the optimization phase.

In the example presented in this paper, the database research algorithm is run to determine the scenario that minimizes better the function $f(x)$. Figure 4 represents the values corresponding to each scenario simulated.

The results of the database search show that the Scenario D2 is the best scenario among all the scenarios simulated. Indeed, it presents a global evaluation value between $4 \%$ and $80 \%$ less than the other scenarios.

\subsection{Business models}

\subsubsection{Vienna - Business model for the reuse of waste heat}

Due to the novelty and complexity of the energy system proposed in the Vienna case, a new business model has to be developed. A centralised structure is considered the most suitable because of the small number of potential participants in the local heat market and the absence of suitable software solutions for the market operation. A New Energy Service Company (NEW ESCO) has to be established, which is taking over the different responsibilities and is managing the purchase, the distribution and the sales of the heat. The existing ownership structure of the buildings, the heat production units (gas boiler, heat recovery, solar thermal panels and heat pumps) and the necessary equipment will remain but their heat production will be sold to NEW ESCO. Recovered heat from the RTA facility will be used as first option. If the recovery heat production is higher than the demand, the excess will be stored and used later in case that the recovery heat production cannot cover the demand. If the heat-stored tank cannot supply heat under the established quality (temperature level), the other heat producers will be connected. 
The implementation of this system is favourable for all the actors. The consumers will reduce the individual heat-energy costs. RTA will convert its waste heat into a valuable product, and the NEW ESCO will focus on the investment in the adaptation of energy generation units, the heat storages and the district heating network as well as a control system. Additionally, the NEW ESCO could extend the district heating network to other buildings to increase its business opportunities.

The operation will be based on long-term heat purchase and supply contracts in terms of heat quantity and quality. The possibility to supply heat at different temperature levels can increase the number of suppliers due to the inclusion of the heat pumps and the thermal solar system, which can supply 'low temperature heat' to the passive office buildings to cover their space heating demands. For the implementation, the NEW ESCO has to bear large investment costs for the design of the district heating network and the adaptation of the existing heat production facilities. The payback time can last for several years or not be reached, in which case possible support from funding agencies as well as the expansion of the grid to other buildings would lower the risk.

\subsubsection{Helsinki - electricity storage in Kalasatama}

Business model for Kalasatama case is divided to two distinct chronological phases. The first pilot phase composed of R\&D-focused operations separately agreed between the project partners. The pilot phase will last for three years. The second phase is focused on commercialization, during which the capabilities of the Battery Energy Storage System (BESS) are offered to the competitive markets. The execution of the second phase will largely depend on the experiences on the optimal practices obtained during the pilot phase.

The owner and operator of the BESS will be Helen Oy. Fingrid Oyj and Helen Sähköverkko Oy are partners and customers for Helen Oy. The Ministry of Employment and Economy has an auxiliary role in providing funding for the project. The BESS system provider will also be engaged to the R\&D project to optimize the system to meet the specific needs of all the project partners.

During the 3-year project pilot phase, the BESS owned and operated by Helen Oy will serve Helen Sähköverkko Oy and Fingrid Oyj. Helen Sähköverkko Oy is responsible to maintain voltage regulation throughout its distribution network. Voltage is a local attribute, which can be regulated by injecting or consuming reactive power. In addition to voltage regulation, the BESS provides opportunity for electric energy peak shaving. Helen Sähköverkko Oy provides the site for the BESS and pays for the reactive power compensation service.

Fingrid Oyj is the statutory frequency regulator in Finland. Fingrid Oyj is required to maintain power system frequency within acceptable limits. Frequency can be controlled by increasing or decreasing active power. Helen Oy and Fingrid Oyj have agreed on a deal, in which the Helen Oy BESS system will be producing frequency control for Fingrid Oyj.

Utilizing the BESS unit, Helen Oy is capable of producing reactive power compensation, frequency control and peak load shaving as an independent aggregated service. The BESS can be viewed as an alternative power source for conventional reserve power generation. As such, BESS provides the opportunity to reduce the need of conventional polluting reserve power, such as gas turbines, in a frequency control. Due to peak shaving capabilities, the BESS also reduces need for new distribution lines and reactive power compensation equipment. The energy used by the BESS to realize the above-mentioned functions can be produced with renewable energy sources whenever they are available, thus increasing the utilization of environmentally friendly energy production. 
Helen Sähköverkko Oy and Fingrid Oyj require Helen Oy to provide service usability above $90 \%$ during the pilot phase. Usability requirement of $90 \%$ gives Helen Oy possibility to experiment with $10 \%$ of total time in different markets and uses without financial repercussions. Other key activity will be data sharing and communication between partners.

During the three-year pilot contract, partners have agreed to share costs according to the value of service. Helen Oy will be the owner and operator of the BESS and is paid a fixed income from its customers until the end of the three-year pilot programme. This fixed income model reduces the financial risk for the Helen Oy to an acceptable level. The fixed income also ensures the sustainability of the planned operations for the first 3 years.

\subsubsection{Helsinki - next generation district heating network in Östersundom}

The Östersundom business model is based on the idea of a bidirectional district heating (DH) network that is operated by the local DH company. The inhabitants in Östersundom will have the opportunity to produce a part of the needed heat in their buildings themselves by using renewable energy sources such as biomass, pellets and solar energy. In case surplus heat is created, this can be sold to the DH network. When the inhabitants' own heat production is smaller than their heat demand, additional heat is bought from the DH network. Thus, the inhabitants in Östersundom are prosumers of heat. To optimize the utilization degree of heat produced by prosumers, heat storages in the form of small hot water tanks will be installed at the prosumers' sites.

The business model requires close cooperation between the prosumers and the DH company in Östersundom. These two groups are also the main stakeholders of the business model. Other partners incorporated in the model are producers of small-scale heat production equipment, banks and investors and the municipalities of Östersundom. Additionally, organisations and companies in Östersundom also take part in the business model since they are customers of the DH network.

The value propositions of the business model can be divided into two parts: value propositions for the prosumers and value propositions for the DH company. The possibility to use different renewable energy sources and the transparency of the heat production process are expected to be attractive qualities of the business model from the prosumers' point of view. Other value propositions of the business model such as control of heat production and usage and the opportunity to sell surplus heat to the grid are also features that are expected to attract the prosumers. From the DH company's point of view, one value proposition of the business model is that it could attract new customers to connect to the network. Prosumers connected to the DH network would also become more committed to the network. Other values proposed to the DH company in the model are increased security of supply through the capacity of the prosumers' heat production equipment, the possibility to buy cheap excess heat from the prosumers and positive PR.

The investments needed for the implementation of the business model are rather large, since both investments in the district heating network and energy production devices are large. Therefore, the payback time for the investments will be long or payback may not be reached for all investments. The operating costs are based on fuel costs and other costs such as labour costs and the size of them depend on the fuel price. A functional and efficient cost structure would facilitate the provision of affordable heat for the prosumers and end users. The revenue streams of the business model are decided in the contracts done between prosumers and DH company and DH company and organizations and companies in Östersundom. 


\section{CONCLUSIONS}

\subsection{District energy modelling}

The modelling of the micro-district heating network of Vienna case presents an example of one possible use of the finished CITYOPT tool. A calculation such as the one presented can help to understand and evaluate the complexity of the interaction between all the components involved from the consumer side as well as from the producer side. The assessment of the different design scenarios possibilities, taking into account different price scenarios combinations is done in the CITYOPT planning tool, through the calculation of several specific and global indicators.

The optimum result, obtained after a database search among all the results from the realized simulations, shows that the scenario which optimized the chosen indicators in a general way involves the DH of Vienna with an operation at the prices combination 2. However, whenever the DH of Vienna is not considered, the global results related to the scenario with only the high-temperature storage and the scenario with both high and low-temperature storages appear to be very close. In that case the evaluation function calculated for each case is not enough and an optimization regarding a specific indicator has to be run.

From a modelling point of view, the CITYOPT tool is very flexible and can perform various simulations and optimizations according to the user needs. The studied case was not very complicated, but nevertheless the CITYOPT tool provided results that were not easy to foresee.

\subsection{Business models}

The value propositions of the developed business model in Kalasatama are several: the BESS system gives a chance to avoid the use of expensive reserve power, less reserve power capacity is needed and less transmission line and power grid investments are needed. The size of the considered BESS is quite unique and the operating costs are quite low. However, the purchasing of a BESS system requires large investments. Overall the BESS system is still far from profitable in commercial operation but the business model studied here offers insights into how and what kind of services BESS operators might offer as technology progresses.

The value proposition of the business model in Östersundom includes an opportunity for the inhabitants to produce heat from renewables themselves thus increasing the share of renewable energy in the network. The inhabitants also know the origin of their heat and their awareness of the heat consumption is raised. The value proposition for the DH company is a possibility to attract new customers and an increased commitment to the DH company among the customers. Sources of waste heat may also prove to be lower in cost than conventional heat production. However, for most buildings, the investments needed for both the DH network and heat production units are so high that they are not likely to reach financial viability in the immediate future.

This business model may be sensible under two sets of conditions. The first is as a test bed for new technology to test new solutions to see which are the likeliest to mature to profitability. This could justify public support for the project. However, other locations could be explored to see if profitability could be better elsewhere. The other possibility is that over time the price of technology comes down or the price of energy raises enough to allow profitability for the investments. Many technical solutions envisioned in this business model are, while available, not yet installed in such large quantities that the prices would have been brought down by competition and mass sales. 
The Viennese study case is not entirely different from the Östersundom, but it is focused on a local district heating network for a group of office buildings with utilisation of waste heat from a train testing facility. Under the new business model, the actors buy and sell heat to and from a new central entity, a NEW ESCO that manages the purchase of heat, takes care of the distribution as well as sales to the customers. The main aim is the coverage of the full heat energy demand of the involved consumers on site by utilising the available waste heat and heat from other existing energy generation units included in the system. The sales of the heat energy will be based on a long-term contract. For the implementation the NEW ESCO has to consider large investment costs such as the district heating system including storage needs to be designed and implemented and the existing energy production facilities adapted. Therefore, the payback time is likely to be very long.

\section{REFERENCES}

[1] City of Helsinki, Information about the development of Kalasatama, Online, available at http://www.uuttahelsinkia.fi/fi/kalasatama/perustietoa

[2] Östersundom toimikunta, Kaavaselostus/ehdotusvaihe - Östersundomin yhteinen yleiskaava, 2014. City planning department, Helsinki.

[3] Osterwalder, A., Business Model Ontology, Université de Lausanne: Lausanne, 2004.

[4] Osterwalder, A. \& Pigneur, Y., Business Model Generation, Modderman Drukwer: Amsterdam, 2009.

[5] OIB Richtlinie 6, Energieeinsparung und Wärmeschutz Oktober 2011, Online, available at http://www.oib.or.at/sites/default/files/rl6_061011_2.pdf

[6] OIB Richtlinie 6, Energieeinsparung und Wärmeschutz Marz 2015, Online, available at http://www.oib.or.at/sites/default/files/richtlinie_6_26.03.15.pdf 